\title{
Interculturality in Online Learning: Instructor and Student Accommodations
}

\author{
Gulnara Sadykova \\ Kazan Federal University \\ Carla Meskill \\ University at Albany, SUNY
}

\begin{abstract}
As more distance education courses broaden their reach across borders, the chances of online classes being multicultural are high. This means that more often students may find themselves in courses designed for and by a host culture that differs from their own regarding its approach to teaching and learning. Compounding the difficulties inherent in a novel cultural environment and its unfamiliar forms of academic discourse are challenges represented by the medium itself. This yearlong case study examines the experiences and reflections of a Chinese graduate student and her U.S. instructor-specifically, the accommodations both made to mediate differences and mitigate these challenges. Analyses suggest that when both parties take differences into account and exercise thoughtful accommodations relative to both the challenges of the online medium and language socialization, positive learning experiences can result.
\end{abstract}

Keywords: interculturality, online teaching and learning, instructor-student interaction, international students, academic discourse

Sadykova, G., \& Meskill, C. (2019). Interculturality in online learning: Instructor and student accommodations. Online Learning, 23(1), 5-21. doi:10.24059/olj.v23i1.1418

\section{Interculturality in Online Learning: Instructor and Student Accommodations}

According to the Institute of International Education, 1,078,822 non-U.S. students studied in U.S. colleges and universities in the 2016-2017 academic year (Open Doors, 2017). The share of international students' total enrollment has increased from $1 \%$ to $5 \%$ in the last 75 years, and that number grew by $85 \%$ over the last decade. The U.S. continues to lead in international enrollments in offering online courses beyond its borders. Clearly, online education is popular. Successful participation and performance in online courses, however, depend on a range of complex factors (Shea et al., 2013). When online courses are well designed and orchestrated, they can foster dynamic, socially and culturally situated communities that study in multimodal ways that include forms of interaction distinctly different from live, face-to-face classrooms. Socialization into online learning communities is, likewise, distinct in the mode and manner in which it takes place. When such communities include students who are not from the culture which offers the course, nor are native speakers of its instructional language, this socialization becomes doubly challenging (Levy, 2007; Warschauer, 1998). Where discursive practices and their attendant cultural norms dictate, then intentions, power, investment, and learning outcomes diverge and confusion can consequently 
result. Informed efforts to develop adaptive strategies and practices, what we call accommodations, help in this regard. Instructors' management, mediation, and accommodations of students' challenges matter as both educators' and students' roles continue to change (Blake, 2013; Salmon, 2004; Dzubinski, 2014). In short, contemporary online MOOCs and courses are rarely monocultural and thus present a number of potential challenges. We first discuss those challenges in terms of the online medium, and then in terms of the specific challenges attendant to the academic socialization of students whose home language and culture differ from that of the instructor and course, as is the situation in our case study.

\section{Challenges for International Students in Online Courses}

Both students and their instructors come to instructional venues with a set of expectations as to what instruction should look like. Both have been socialized into their respective academic discourse communities. By the time a student reaches graduate-level study, such academic socialization has been continuously reinforced over decades. Academic socialization online has been examined from the perspective of the roles each party plays in instruction. Traditional teacher-centered approaches, whereby instructors assume the dominant role, have not been generally accepted by Western online educators. Instead, a learner-centered approach, based on sociocultural views of learning, prevails (Meskill \& Anthony, 2015; Palloff \& Pratt, 1999; Ruey, 2010). Moreover, because the U.S. is a culture with low power distance (Hofstede, 2011), a U.S. instructor generally assumes a less authoritative position than that of other cultures with high power distance. Such instructors are more likely to treat their students as equals (Neuliep, 2009). As a result, U.S. online courses may be places where the instructor passes leadership in course discussions and other activities on to students.

\section{The Medium}

"Internet communication tools are not neutral media" (Thorne, 2003, p. 38). Ways of speaking, writing, and understanding continue to be shaped through and by human practices with them. For international students, then, the double challenge of a new academic culture in tandem with communication in a unique and often unstable medium is significant. Indeed, successfully completing an online course assumes a number of qualities and capabilities on the part of learners. They must be sufficiently committed to work at understanding material without the immediate physical presence of an instructor and peers. This implies skills, abilities, and commitments typically associated with autonomous learners (Lin, Zhang, \& Zheng, 2017; Reinders \& White, 2016). Depending on the student's country of origin, this constellation of abilities may be absent or markedly different from that of the country hosting the course and its instructor. Such differences can clearly deter student success. Difficulties in interpersonal communication and power distribution, and dissatisfaction with lack of instructor involvement are some of the challenges reported by instructors with international students in their online courses (Biesenbach-Lucas, 2005; Chen, 2006; Sadykova \& Dautermann, 2009; Shattuck, 2005; Ware \& Kramsch, 2005). It is also evident in the literature that international students need more time and their instructor's encouragement to complete online assignments, such as discussion posts or papers (Zhao \& McDougall, 2008), as well as consideration of potential linguistic and cultural misunderstandings (Belz, 2005; Duff, 2010; Sadykova, 2013; Shattuck, 2005; Wang, 2007). Finally, having individuals from differing cultures communicate online can result in cultural contestation with fewer mediational means (e.g., a nonverbal, physical context) to mitigate misunderstandings (see, for example, O’Dowd, 2003; Ware \& Kramsch, 2005; Warschauer, 2002).

\section{Socialization Into Academic Discourse}

Challenges for students from Eastern, Confucian traditions who find themselves in Western classes are both philosophical (i.e., how education is understood and enacted) and 
quotidian. Western Socratic approaches to education emphasize critical thinking and problem solving, whereas a Confucian approach sees the accumulation of content knowledgeknowledge that comes from authoritative sources - as primary (Greenholtz, 2003; Hu, 2002). Moreover, in the context of online education, the quality of learning experiences, as understood by many Western online educators and scholars, is directly linked to social presence and teaching presence, which along with cognitive presence, constitute the Community of Inquiry (CoI) framework (Garrison, Anderson, \& Archer, 2000), which has been widely used as a leading theoretical model guiding studies in online learning in higher education (Shea et al., 2010). The CoI presupposes a high level of interaction and engagement with the instructor and among peers, which may bear little resemblance to Confucian practices.

This study examines the experience of one graduate student who was once a Confucian learner but who socialized into the Socratic context of an online U.S. graduate course and beyond.

\section{Perspective}

Hofstede (1986) argues that "as teacher/student interaction is such an archetypal human phenomenon, and so deeply rooted in the culture of a society, cross-cultural learning situations are fundamentally problematic for both parties" (p. 303). Our cross-cultural inquiry set out to examine the potentially problematic interactions of a native Chinese student, Cathy, acclimatizing to Western-style online learning and the efforts on the part of her online instructor to mediate her challenges. In our effort to situate, fine-tune, analyze, and discuss our interpretations of these data, we employ a Vygotskian sociocultural lens that sees learning as a quintessentially social process (Vygotsky, 1981). We specifically employ the later work of the Scollons, whose discourse approach to the study of intercultural communication sees the individual and their culture as indivisible, in employing a single unit of analysis (Scollon \& Scollon, 2001). While their work focuses primarily on group interactions, they examine the ways that ideological positions of discourse systems factor into the interpersonal communication of members of differing, interacting groups. Their constructs are thereby useful for our examination of a single individual interacting within a cultural context distinctly different from her own.

In our study of Cathy, we set out to examine if and what kinds of accommodations could be made by both a U.S. instructor and her Chinese graduate student to overcome the dual challenges of the online environment and the complex process of academic socialization. The research question, What did the instructor and student do to accommodate these challenges in a semester-long graduate course? guided study design, data collection, and how we interpreted them. The following section describes the methods employed to address this question.

\section{Methods}

The student participant for this study, Cathy, was recruited via a larger, separate research initiative reported in Sadykova (2013). That larger mixed-methods study involved the survey of 12 international students and follow-up interviews with five of them, including Cathy, a native of Shanghai, China. A criterion sampling (Patton, 2001) was used to identify those international students who took at least one fully online course in a U.S. university.

The survey and follow-up interviews revealed that Cathy could become an important key informant for an in-depth case study. On the one hand, being a student from China, the largest segment of international students in the U.S., she represented a typical case. On the other hand, the data collected during the first stage of the study showed that Cathy was participating in her first U.S. online course while being in her home country. Moreover, she 
intended to change her status to on-campus student after completing the online course. Thus, Cathy made an excellent candidate for purposeful intensity sampling, as she "manifest[ed] the phenomenon intensely, but not extremely" (Patton, 1990, p. 182). Cathy's online instructor happened to be a research advisor of one of this study's authors, which made the collection of data more feasible and convenient. Therefore, Cathy was contacted again and invited to be the key informant for the case study. Upon arrival in the U.S., Cathy was asked to keep a reflective journal to record how her previous online experiences prepared her for on-campus learning. Her learning experiences were further discussed in a 59-minute face-to-face interview. Cathy's online instructor's interview responses, as well as the archived course logs of eight U.S. students who had interacted with Cathy which were retrieved from the online course, enabled the assembly of rich case study data.

\section{Settings}

Cathy's experiences are examined in two distinct settings: the online graduate course she completed while still in China and the face-to-face courses she completed in the U.S. All courses were offered via a school of education. The online graduate-level course was designed and taught by a U.S. instructor and taken mostly by in-service and preservice teachers from a variety of school disciplines. This was a spring course that lasted the whole semester and required no physical presence of students on campus. The course was delivered on the Blackboard Learning System (BLS), which allows course designers and facilitators to build and manage learning content and to provide synchronous and asynchronous tools for computermediated communication.

\section{Cathy, the Key Informant}

The key informant of the study was a female international student from Shanghai, China, who chose to go by her nickname, Cathy. The online course under analysis was the first U.S. course she took while residing in her home country; thus, she was a neophyte regarding online learning in U.S. academic culture. She had not lived in the U.S. before taking an online course but had visited the country several times when leading groups of Chinese students. It was also Cathy's first formal online learning experience.

Cathy held a bachelor's degree in international economies and foreign trade from a Shanghai institution. However, she chose to pursue a new career in the field of education and therefore enrolled in a master's program in TESOL (Teaching English to Speakers of Other Languages) at a large U.S. university. This program enabled her to take some of the courses fully online but required residency for other courses. Therefore, after taking one course online in the spring semester, she arrived in the U.S. and spent the full fall term taking courses on campus.

When asked to describe her individual culture, Cathy emphasized her affiliation with Asian culture and mentioned her large family consisting of four generations. While in her first interview Cathy wrote that she had no religion, in a later interview she disclosed that she could be described as a follower of Confucianism and that the Confucian concept of respect and obedience to authority may have shaped, perhaps even on a subconscious level, her learning.

\section{Cathy's Online Instructor}

The instructor who designed and facilitated the online course is also second author of this paper. She is a full professor at a large research university. She characterized her own culture as WASP (White Anglo-Saxon Protestant). In her early career, she worked as an ESL (English as a second language) instructor. This experience helped her to become "hyper aware of structures and idioms that non-native speakers may not have mastered" and taught her to alter her writing style and language when composing messages intended for international 
students. She has extensive experience in conducting research in language education and designing professional development training for faculty working with English language learners. This experience, as well as several years of online teaching, extensive international travel, and fluency in two foreign languages, apparently provided the professor with knowledge and skills needed to effectively design and manage a distance learning course that included international students.

\section{Data Analysis}

The yearlong reflections, interviews, and follow-up interviews were analyzed by iterative thematic development and by seeking patterns and categorizations. In response to the research question, What did the instructor and student do to accommodate these challenges in a semester-long graduate course? data were first sorted thematically. Scollon and Scollon (2001) discourse analysis techniques were then used to examine the communication strategies Cathy employed in the context of learning. Specifically, we examined how Cathy maintained her face, "the negotiated public image, mutually granted each other by participants in communication event" (Scollon \& Scollon, 2001, p. 45), when communicating with the instructor and peers. In the Scollons' framework, there are two sides of face: the need to be involved in communication and the need to show one's independence and let the other side be independent. We followed the Scollons' classifications and identified strategies of involvement, such as asking for opinions or claiming a common point of view, and strategies of independence, including apologizing or using family names.

The following section provides and discusses representative data illustrating the emerging themes of instructor and student accommodations to the challenges attendant to the medium and to academic discourse socialization.

\section{Results}

\section{Instructor Accommodations}

The professor's teaching philosophy aligns with sociocultural ideas underscoring the importance of human interaction. "I believe the most compelling dimension of online teaching and learning is the human one," she stated in her interview. Therefore, online whole-class and small-group discussions and teamwork were prominent in the course that Cathy happened to sign up for. Accommodations practiced by the instructor related to the concurrent challenges of the medium and academic socialization for international students will be discussed first, followed by discussion of accommodations made by Cathy in her role as an international online student.

The medium: The human dimension. The instructor reported that she felt quite strongly about the human dimension in teaching and learning. This, she stated, is paramount, be it live or online, and she has dedicated over 20 years to designing and teaching online courses by exploiting the medium's possibilities accordingly. At every opportunity, she stated, "there is productive interaction." At every opportunity, she integrates her instructional voice conversationally to guide and assess learning. Her courses are chiefly "generative discussions and teamwork with the public exchange and development of ideas as the key focus of online courses and I design them accordingly."

The medium: Public referencing. As part of her emphasis on interaction, the instructor publicly commented on students' assignments that she posted for whole class review. In her comments she did not just evaluate the work, but rather asked students additional questions that required them to think further about the topic or to provide more examples: 
A very nicely composed essay overall. Your articulation of the differences between instructional delivery and instructional conversation was of special interest to our topic at hand. Can you provide examples from your teaching of Spanish that exemplify good instructional conversation?

Please say more about your vision of pedagogical applications for the facial recognition software! Please!

She also required that students respond constructively to one another's work which was formatively evaluated, thus exploiting the assessment dimension of asynchronous online teaching.

The medium: Multimedia resources. Whenever the opportunity presented itself, she reports, she referred students to multimedia sources as illustrations and to amplify course content:

For those of you for whom ELLs and technology is a novel notion, I'm attaching a study that portrays optimal integrations and uses. Also, here is a link to a video that shows ELLs and their ESOL teacher learning around computers.

Multimedia integration, while appropriate for and supportive of the learning of all students, is particularly additive for non-native speakers of the common language. Indeed, visuals continue to be a major tool to aid language comprehension and learning (August, Artzi, \& Mazrum, 2010; Meskill, 2002).

Academic socialization: Direct instruction. In response to what the instructor perceived as awkward attempts on Cathy's part to participate congenially in online group discussions, the instructor provided a detailed evaluation of Cathy's performance in the first part of the course and offered a number of specific strategies to improve the quality of her discussion posts. Specifically, she recommended Cathy do the following:

- comment on the group product of all groups, not just yours or one other;

- restrict congratulatory comment;

- try to move the discussion forward through clarification questions or thoughtful questions that inspire further consideration of the topic;

- share personal experiences that can serve to reinforce or expand the information.

These recommendations show that Cathy's instructor saw the need to provide her international student with direct instruction on how to make posts align with U.S. academic discourse.

Academic socialization: Linguistic precision vs. language variation. Based on her experience teaching non-native speakers of English, the instructor was very attuned to structures and idioms that non-native speakers might not have mastered. She consequently altered her writing to accommodate international students. To encourage linguistic precision on the part of all students, the instructor continually posted a remind box stating the following:

Edit before you send! Because this course is a graduate course, it is expected that you will carefully read and edit your work prior to sending it. Every message that you post should first be composed using a word processor to prevent cosmetic errors; this way you can concentrate on demonstrating your highest quality writing. "Chat style" language is not acceptable.

While expecting linguistic precision from all students, the instructor was tolerant of the language variance of international students, specifically of Cathy's English, which was not without flaws in terms of grammar, vocabulary choice, spelling, and style. To illustrate the 
extent of interlanguage variation, Cathy's posts and responses to interview questions are left unedited throughout.

Cathy's instructor did not see English proficiency as having any negative impact on Cathy's course performance. There were no posts in which the instructor asked Cathy to revise her English and resubmit posts or assignments. In fact, Cathy herself also felt that her English was adequate for learning in an English-only environment. This was evident from the survey she completed and from her interviews.

Academic socialization: Cross-cultural issues. Engaging in conversations about culture - be it with peers or instructor - might be highly desirable in a multicultural classroom (Banks \& Banks, 2010), and Cathy was lucky enough to have an instructor who understood this and provided space for sharing culturally specific knowledge. In the interview, Cathy's professor explained that in her classes she purposefully sets up activities that enable "international students to have a voice ... to be the experts, to present other ways of being and knowing the world" and that this aspect is critical in her teaching. Cathy's online instructor pointed out that "a cross-cultural dimension to the content and assignments" was one of the factors that helped an international student fit well into the course.

Academic socialization: Flexibility with deadlines. Cathy's online professor also chose to be flexible with assignments and deadlines. She offered Cathy an alternative plan for assignment submission when Cathy asked for flexibility due to her traveling demands. This shows that the instructor chose not to exercise her authoritative power as some strict professors might do, but rather preferred to negotiate terms of meeting course requirements without sacrificing the course learning outcomes or the students' responsibilities outside of school.

Data, particularly from student-instructor conversations, suggest that Cathy appreciated the efforts on the part of her online instructor. Evidently, the first part of the course was extremely challenging for Cathy, and the instructor's support was of significant importance. Cathy felt comfortable enough to contact her instructor on several occasions. Among 13 messages addressed to the instructor, nine were private messages and four were replies within whole-class discussions. The private messages to the instructor were related to missed deadlines, misunderstood assignments, and the like. The post below demonstrates that Cathy perceived the instructor and her graduate assistant as approachable and understanding and that she was thankful for their reminders about assignments:

Professor, I am afraid I have just missed this part. Give me some time to think it over and participate in it. Thank you for your kind reminder.

\section{Summary: Instructor Accommodations}

In sum, the instructor made a number of accommodations that helped Cathy and other international students to overcome challenges of online academic socialization (Table 1). The instructor reports taking advantage of the static, archived nature of the medium to study posts and to develop appropriate scaffolds and responses. In short, the time she could spend considering responses to Cathy was valuable in that well-developed replies assisted in Cathy's successful negotiation of the medium and her socialization into the academic discourse. When it comes to international students, and to students overall, the instructor sees herself as a cultural intermediary, with culture always holding great promise and possibilities for instructional enrichment regardless of the subject area. 
Table 1

Summary of Instructor Accommodations

\begin{tabular}{|l|}
\hline Instructor Accommodations \\
Medium \\
- emphasis on the human dimension \\
- integration of multimedia resources in \\
discussions \\
Academic Socialization \\
- direct instruction \\
- linguistic precision vs. tolerance to language \\
- integration \\
- opportion of cross-culture discussion at every \\
\hline
\end{tabular}

\section{Cathy's Accommodations}

The literature suggests that international students are at risk due to a lack of previous experience studying in the U.S. education system. They therefore might need additional support to function in U.S. academic discourse (Zhang \& Kenny, 2010; Zhao \& McDougall, 2008; Wang, 2007). Cathy felt that she needed extra time to get "adjusted to a completely new learning style, requirement, evaluation, etc." Thus, the lack of adequate academic socialization to language and academic discourse conventions surfaces as the impediment to learning. The medium, however, to some extent mediates this due to its static, archival nature, whereby students can read and reread material, view and review videos, compose and recompose their contributions and assignments as many times as their waking life allows. This is in contrast to the rapid-fire nature of live classes, where what gets spoken is transient.

The medium. For Cathy this was the first online course she had participated in, and she needed to learn how to use the interface and tools. While her technical background was not specifically examined for this study, the data indicate that Cathy was technically savvy and did not have technical difficulties when learning online. She nonetheless had to adjust to the medium as a venue for learning with others. This she reported as more challenging than later when communicating with her U.S. peers in the live classroom.

Continuous access to course content. Cathy's unique experience as first a novice fully online student living in her home country and then as a face-to-face student studying on a U.S. university campus provides an interesting perspective on the affordances of both learning environments. Here is an insightful quote from her interview:

I think online environment have advantage of being the words put there all the time, so that you can check always, whenever you want. If it is a lecture or presentation given by a professor or students, it lasts 5 or 10 minutes and if you miss it you just miss it.

Access to professor. Cathy notes that the online medium makes learning more independent while allowing students to ask for instructors' help after trying to figure out the topic on their own. That is, the online medium allows a longer distance between the need for help and the request for help: 
I found that actually, the professor, well, they actually talk a lot about in the classes, but the content period is to help you explain further what they have assigned to you to read in the previous class. I would say that if it is online, this job is totally yours. I mean if you just can't understand the reading, you have to read it again yourself and if your fail you can check with the professor...

Cathy used this feature often and well as she negotiated the online course and its norms and requirements, and thereby learned what she needed to do to make the learning experience work well for her.

Access to resources. When working to make sense of both new scholarly concepts and the discourse that expresses them, Cathy reported accessing online resources to assist her comprehension: "There are a lot of resources online that students can use." She also frequently used her online peers as resources, as reported in Sadykova (2014). Moreover, Cathy perceived the online environment as a useful medium for improving her language proficiency. "Honestly, as a foreign speaker, I am not very confident about my English literacy. I hope I can learn from you day by day," Cathy confessed to her peers.

Academic socialization. One of the largest hurdles for students from differing backgrounds is becoming acclimated to and socialized into the academic community. As revealed in the following sections, Cathy's efforts in this regard were significant.

Time accommodation. As noted previously, Cathy recognized early on that she would need to dedicate much more time to fulfilling the requirements of the online course than she was accustomed to. She actively and successfully negotiated this with her instructor. Cathy reported needing more time to get "adjusted to a completely new learning style, requirement, evaluation, etc." which has been reported elsewhere for students new to online learning (Sadykova \& Dautermann, 2009; Smart \& Cappel, 2006).

Queries and other communication strategies. As illustrated earlier, Cathy saw the opportunity to continuously contact her professor as a tremendous asset and used the mail function in the course to ask many questions:

Professor, I like the idea that "in-class learning was complemented by online group problem solving". However, I am also interested to know what the role we teachers should play during this process. Should we be engaged in the online groupwork as an active participant, or rather we are facilitators or guides by implementing various instructional conversation strategies and do not have comments upon any of their thoughts and responses from students?

Asking questions was one of the communication strategies of involvement (Scollon \& Scollon, 2001) that Cathy actively employed when interacting with her instructor and peers. Her involvement was also evident when she (1) showed strong interest in other participants' affairs by directly asking for their opinion (e.g., "What would you think of it?"); (2) pointed out common in-group membership (e.g., "I am so proud of being a member of this family"); (3) claimed a common point of view (e.g., "In China, we share the same problem, even to a greater extend"); (4) expressed reciprocity (e.g., "As you said, we have to keep in mind the strengths of new literacies, stressing its prominent role in global communication and sharing"); and (5) expressed optimism (e.g., "Let's take the responsibility of adults and hope for the best for our children's future").

Analysis of the online discourse revealed that communication strategies of independence (Scollon \& Scollon, 2001) were less prominent in Cathy's interactions with the instructor and peers. However, she utilized these strategies when (1) making minimal assumptions about the wants, needs, or interests of others (e.g., "If you have any ideas about 
our assignment, it is very welcome"); (2) minimizing threat (e.g., "Thank you.... but it seems I did not receive your invitation. Can you try again."); (3) apologizing (e.g., "Very sorry for the unconvenience I caused to the group"); and (4) using family names and titles (only when referring to the instructor).

Thus, Cathy's posts demonstrate her ability to mitigate the lack of face-to-face interaction and the need to learn more about U.S. academic discourse with the help of the communication strategies of involvement

Metacultural awareness. Cathy clearly exercises metacultural awareness throughout her U.S. graduate school experience. This is illustrated in the following journal entry, in which she responds to an uncomfortable incident where cultural misunderstanding occurred:

The more we get to [know] each other on racial and cultural level, the more possible that conflicts and misunderstandings amongst class could be avoided. This is to say to be a good teacher who can successfully accommodate this foreign student, I would firstly try to establish personal friendship with him by showing trust upon him... I'd like to advocate class discussion within class of culture diversity by making comparison between the main culture and the foreign. It is only through adequate debating aroused from doubts and unknowns that students can learn from each culture and thus misunderstand and disrespect could be avoided.

No doubt Cathy appreciated such a culture-rich learning environment. Her posts demonstrate that she is a strong proponent of culturally sensitive teaching and learning in which the instructor takes on the role of cultural intermediary and expert.

Clarification. Cathy's other posts to the instructor within the whole-class discussions illustrated her appreciation of the instructor's attention to her ideas and her desire to further clarify the question under discussion:

Professor [instructor's surname], It sounds like "blended learning" is centered on f2f conversation with an extension of online class. Do I make it right? We have no this kind of class in China now, with our technology use in education still lagging behind. I am wondering if it has already been widespread in US, does it work better compared with full online courses or $\mathrm{f} 2 \mathrm{f}$ class format.

This post also shows that for Cathy the instructor was an important source of knowledge about U.S. culture and particularly U.S. education. Not knowing much about the system of education in the U.S. and seeing her instructor's engagement in conversations with her, Cathy took the opportunity to clarify the term "blended learning" and further satisfy her hunger for learning about U.S. education.

Confucian identity. Cathy was particularly insightful and articulate concerning her development as a Western-style learner, and she reports much of this having occurred during her initial online course. Having grown up and been educated in China, Cathy joined the U.S. course laden with epistemological and moral beliefs associated with Confucianism. For example, she portrays the role of the instructor in China as that of an expert authority, who preselects the content (based on curriculum requirements) and delivers this prepackaged knowledge in the form of a lecture. Students' active involvement is very limited, ruled by the instructor, and might be prohibited when seen as disruptive to the harmony of the group:

I find classroom teaching [in China] is more teacher-centered, where students play a rather passive role who are used to accept whatever knowledge teachers endow with and they seldom challenge so called "authority"... Doubts or challenges from students are not exactly welcome... The class is more like a one-way lecture delivering... 
According to Cathy, the content of the courses in China is often theory-driven, and "teachers spend a lot of time in explaining details of certain points at the sacrifice of group works, projects or experiments."

Cathy explains the adherence to teacher-centered instruction in the Chinese classroom as due to large class sizes and the assessment system: "Students here are exam-oriented and they are forced to do a large amount of written homework everyday in order to be able to perform well in the final college/middle school entrance examination." Because "exams historically drove the educational system of the Chinese Empire" (Suen \& Yu, 2006, p. 46), it comes as no surprise that teachers feel responsible to train students accordingly.

Chinese classrooms, however, seem not to be organized only as lectures. While describing the Chinese classroom as teacher centered, Cathy also mentions activities that involve teacher-student and student-student interactions:

In the Chinese classroom, students are mandatorily required to receive a lot of input and take examinations, and at the same time, they are also encouraged by teachers to produce communicative ideas by carrying out interaction between the instructor and the student or among all the individuals. Besides, teachers would also choose to do pair or group work as an alternative.

When describing a good teacher in China, Cathy also mentions the ability to "stimulate students' curiosity and creativity by using a good variety of teaching methods and interactive activities in class," a comment that does not quite align with her earlier description of the Chinese classroom as based solely on lectures.

The juxtaposition of these data indicates that group work and class discussions are not nonexistent in Chinese classrooms but are limited: They might occupy very little time, or be used only in classrooms conducive to group activities, such as language courses, or be part of the repertoire of only a few teachers.

Overall, Cathy sees both benefits and drawbacks of teacher-centered, exam-driven, and often theory-based instruction in Chinese classrooms. She is most dissatisfied with the authoritarian role of the instructor, which in her own words "is in its greatest need of change, given that it could hinder the development of students' creation, imagination and independent thinking which are all crucial elements for their future academic growth." However, she realizes that such a change may not happen very quickly due to deeply rooted Chinese traditions in education and the scale of reforms.

Cathy advocates that Chinese instructors assume the role of reformers and start the bottom-up process of "tremendous ideological transfer" from purely teacher-centered learning environments to more "individual-centered." In this process, Cathy would not like to completely abandon the instructor's role as the knowledge expert and a peacekeeper because she believes that a good teacher in her home country should act "as a captain who is in command of skills of keeping the whole class in harmony and order while encouraging individual imagination." According to Cathy, maintaining control enables instructors to avoid students" "endless and distractive talking" that may result from spontaneous class discussions in a student-centered classroom, as Cathy experienced in her U.S. on-campus classes. Reforms, to Cathy's way of thinking, should not be made at the expense of solid content knowledge.

Cultural differences become tools. Cathy's cross-cultural awareness affords her useful insight into similarities and differences to which she adapts and employs as tools to further her socialization. She confessed the following:

At the very beginning I felt very uncomfortable with this kind of learning style in the US because in China what we do is listen to lectures and we never ever try to 
challenge him whenever we want. It's crazy, you know. We just obey, listen, observe very attentively all the time... But in the US I found that students always raise hands whenever they want, just cut and jump and do everything but it's crazy to me. [Laughing]. But I am learning it. I actually did it. [Laughing together]... But gradually I found out that this is very interesting interaction process and I found that professors actually prefer this, they like this.

Not only did Cathy learn fundamental Socratic practices of questioning and expressing opinions, but she was also able to use the online environment as a useful tool for her gradual transition to Western pedagogy:

I would say that learning experience online last semester really help me a lot. I had almost no transition period that I would have to go if I hadn't had that online experience when (compared) to a student who would be suddenly exposed to American culture without any prior experience in a foreign country before. They have to overcome a lot of difficulties like cultural differences or the accent they are not very comfortable with, or other stuff about culture, about academic things, the curriculum, the way teacher lectures students, something they are not very familiar with. For me, I had this experience online before and I know how Americans actually learn and teach...

\section{Summary: Cathy's Accommodations}

In order to mitigate her many difficulties as a novice online student, Cathy used a variety of accommodations (Table 2): She capitalized on continuous access to course content, her professor, and supporting online resources. As regards academic socialization, Cathy used this opportunity to critically examine her beliefs and those of her academic hosts as she adapted to new discourse practices. She also asked for more time to do her work, as well as for clarification when needed. As she worked through her changing sense of herself as a learner, she turned challenges into tools, actively employed communication strategies of involvement, and practiced multicultural awareness as part of her personal development.

Table 2

Summary of Cathy's Accommodations

\begin{tabular}{|l|}
\hline Medium \\
- Cathy's Accommodations \\
- access to professor \\
- access to resources \\
Academic Socialization \\
- recognizing need for more time \\
- employing communication strategies of \\
- involvement \\
- practicing metacultural awareness \\
- working for clarification through her Confucian identity \\
- turning cultural difference into tools \\
\hline
\end{tabular}




\section{Discussion}

Both the course instructor and Cathy made accommodations to ensure Cathy's intellectual growth and academic success as an online graduate student. As regards the medium, the instructor emphasized the human dimension of teaching and learning through activity design and mediation. Further, she integrated multimodal resources into discussions and made public interthread referencing throughout the course. In terms of academic socialization, she used direct instruction to assist Cathy in accomplishing course requirements when she was struggling. She emphasized linguistic precision for all students, thereby encouraging her responsiveness to models of the online community's discourse. However, she was tolerant of language variation in Cathy's posts that demonstrated deviations from Standard English. Recognizing that Cathy struggled with the amount of work required by the course, she was flexible with deadlines. Finally, and perhaps most importantly, she integrated cross-cultural discussion at every opportunity, affording Cathy multiple and ripe opportunities to explore and reflect on herself as a learner in two distinct academic cultures, Confucian and Socratic.

Cathy, for her part, took advantage of the online medium's affordances of having all course content continuously accessible as well as continuous access to her professor, whom she contacted frequently. She accessed resources as needed to support her learning, including improving her language skills. As far as academic socialization is concerned, in addition to accommodating time pressures, asking questions, and employing other communication strategies of involvement, Cathy exercised her growing metacultural awareness in working through her Confucian identity. Moreover, she was able to use her online learning experience as a jump start in her development as a Western-style learner. In short, both instructor and student took what could have otherwise been hindrances to a successful academic experience and transformed these into affordances that supported Cathy's development as an international student in a new learning context.

Culturally determined beliefs about teaching and learning do shape instructional and learning practices. U.S. instructors develop learning environments that value the Socratic method of questioning, the generation of ideas, and the co-construction of knowledge. In such an environment, critical thinking and problem-solving skills are at the fore. However, these skills and their required dispositions might not be well developed among those international students who were educated in cultures that adhere to the Confucian philosophy or other cultural orientations, where the accumulation of knowledge from authoritative sources is a goal of learning, habitually attained by means of passive listening and memorization. Such approaches serve to mold learners' morals and prepare them to serve the needs of the group they belong to, but they do little to prepare them for more Socratic approaches to education.

Lack of expected learning skills (or psychological tools, in Vygotsky's terms) may significantly complicate the learning experiences of a student, as was evident in Cathy's case at the beginning of her online course. Direct instructor involvement in such cases is crucial to ensure that a student is provided enough scaffolding to avoid failure. Once students understand and learn the tools of the host culture discourse, they may become its avid followers and promoters (see Sadykova, 2013).

\section{Implications}

As is clearly illustrated in this case study, it is possible to take what are otherwise seen as challenges to international students in an online course and turn them into affordances and assets. Both Cathy and her instructor were able to accommodate challenges posed by the medium and by academic socialization processes to great effect. Integration of and responsiveness to cross-cultural reflection and conversation were key. 
Results suggest that predeparture courses on socialization into U.S. academic discourse are thereby an attractive programmatic option. They also suggest that U.S. online courses with international students integrate whenever possible discussion of difference and celebration of what is learned therein. Clearly, Cathy sees the instructor's role in avoiding cultural conflicts as critical and regards class discussions about cultures as essential for classrooms that care about cultural minorities. Thus, courses that have a cultural component integrated into the curriculum would appeal to and actively involve international students. An integrated cultural component to any online course, then, is a potential asset for all.

\section{Conclusion}

The bar continues to rise in terms of students' quality of online performance, much of which demands clear written expression, a challenge for non-native speakers of the common language. Measures such as Educationally Valuable Talk, for example, are being employed as part of student assessments in online courses so that all student contributions are strictly evaluated (Uzuner Smith \& Mehta, 2013). Students' posts will be judged against strict criteria that, while aligning with Western Socratic approaches, might appear completely foreign to someone whose cultural background is more Confucian, or more oriented toward high power distance or less individualistic approaches. Awareness of this on the part of U.S. online instructors is critical, as is further research on cultures in contact in online learning. Through Cathy's experiences, we have learned that online educators need to better understand their own discursive practices and their requirements so as to model, guide, mediate, and sometimes explicitly instruct international students in culturally appropriate ways of being and communicating in U.S. academic contexts if we wish to improve completion rates and slow attrition in online courses. Finally, as we witnessed with Cathy and her instructor, both instructors and students can benefit from exercising flexibility and responsiveness in online multicultural settings.

While this research is limited by virtue of its being a single case study, results and inferences are nonetheless valuable in delineating the challenges of intercultural teaching and learning online and, further, how these challenges can be both met and capitalized on in practice. It also suggests the promise of further research on multicultural online education. 


\section{References}

August, D., Artzi, L., \& Mazrum, J. (2010). Improving science and vocabulary learning of English language learners. Center for Research on the Educational Achievement and Teaching of English Language Learners.

Banks, J. A., \& McGee Banks, C. (Eds.). (2010). Multicultural education: Issues and perspectives (7th ed.). New York: John Wiley.

Belz, J. A. (2005). Intercultural questioning, discovery and tension in Internet-mediated language learning partnerships. Language and Intercultural Communication, 5(1), 3-39. http://dx.doi.org/10.1080/14708470508668881

Biesenbach-Lucas, S. (2005). Communication topics and strategies in e-mail consultation: Comparison between American and international university students. Language Learning \& Technology, 9(2), 24-46. Retrieved from http://1lt.msu.edu/vol9num2/biesenbachlucas/default.html

Blake, R. (2013). Best practices in online learning: Is it for everyone. In F. Rubio, J. J. Thoms, \& S. K. Bourns (Eds.), AAUSC 2012 Volume--Issues in language program direction: Hybrid language teaching and learning: Exploring theoretical, pedagogical and curricular issues, 10 (Chapter 2, pp. 10-27). Boston: Heinle.

Chen, C.-F. E. (2006). The development of email literacy: From writing to peers to writing to authority figures. Language Learning \& Technology, 10(2), 35-55. Retrieved from http://scholarspace.manoa.hawaii.edu/bitstream/10125/44060/1/10_02 chen.pdf

Dalton-Puffer, C., \& Smit, U. (2013). Content and language integrated learning: A research agenda. Language Teaching, 46(4), 545-559. https://doi.org/10.1017/S0261444813000256

Duff, P. (2010). Language socialization into academic discourse communities. Annual Review of Applied Linguistics, 30, 169-192. https://doi.org/10.1017/S0267190510000048

Dzubinski, L. M. (2014). Teaching presence: Co-creating a multi-national online learning community in an asynchronous classroom. Journal of Asynchronous Learning Networks, 18(2). Retrieved from https://olj.onlinelearningconsortium.org/index.php/olj/article/view/412/106

Garrison, D. R., Anderson, T., \& Archer, W. (2000). Critical inquiry in a text-based environment: Computer conferencing in higher education. The Internet and Higher Education, 2(2-3), 87-105. https://doi.org/10.1016/S1096-7516(00)00016-6

Greenholtz, J. (2003). Socratic teachers and Confucian learners: Examining the benefits and pitfalls of a year abroad. Language and Intercultural Communication, 3(2), 122-130. https://doi.org/10.1080/14708470308668096

Hofstede, G. (1986). Cultural differences in teaching and learning. International Journal of Intercultural Relations, 10, 301-320. https://doi.org/10.1016/0147-1767(86)90015-5

Hofstede, G. (2011). Dimensionalizing cultures: The Hofstede model in context. Online Readings in Psychology and Culture, 2(1). https://doi.org/10.9707/2307-0919.1014

Hu, G. (2002). Potential cultural resistance to pedagogical imports: The case of communicative language teaching in China. Language, Culture and Curriculum, 15(2), 93-105. http://dx.doi.org/10.1080/07908310208666636

Jung-Ivannikova, L. (2016). Communication challenges learners face online: Why addressing CMC and language proficiency will not solve learners' problems. British Journal of Educational Technology, 47(2), 239-247. https://doi.org/10.1111/bjet.12219 
Kozlova, I., \& Zundel, E. (2013). Synchronous online language teaching: Strategies to support language development. In C. Meskill (Ed.), Online teaching and learning (pp. 99-116). London, UK: Bloomsbury Academic.

Levy, M. (2007). Culture, culture learning and new technologies: Towards a pedagogical framework. Language Learning Technology, 11(2), 104-127. http://dx.doi.org/10125/44106

Lin, C.-H., Zhang, Y., \& Zheng, B. (2017). The roles of learning strategies and motivation in online language learning: A structural equation modeling analysis. Computers \& Education, 113, 75-85. https://doi.org/10.1016/j.compedu.2017.05.014

Meskill, C. (2002). Teaching and learning in real time: Media, technology and language acquisition. Houston, TX: Athelstan.

Meskill, C., \& Anthony, N. (2015). Teaching languages online. Bristol: Multilingual Matters.

Morse, K. (2003). Does one size fit all? Exploring asynchronous learning in a multicultural environment. $J A L N, 7(1), 37-55$. Retrieved from https://pdfs.semanticscholar.org/eea5/06b9cd56b83aedc8e673fbc57a420181c040.pdf

Neuliep, J. W. (2009). Intercultural communication: A contextual approach (4th ed.). Thousand Oaks: Sage.

O'Dowd, R. (2003). Understanding the "other side": Intercultural learning in a Spanish-English e-mail exchange. Language Learning \& Technology, 7(2), 118-144. Retrieved from http://scholarspace.manoa.hawaii.edu/bitstream/10125/25202/1/07 02 odowd.pdf

Open Doors 2017 Executive Summary. (2017). Institute of International Education (IIE). Retrieved from https://www.iie.org/Why-IIE/Announcements/2017/11/2017-11-13-OpenDoors-2017-Executive-Summary

Palloff, R. M., \& Pratt, K. (1999). Building learning communities in cyberspace: Effective strategies for the online classroom. San Francisco, CA: Jossey-Bass Publishers.

Patton, M. Q. (1990). Qualitative evaluation and research methods. SAGE Publications, Inc.

Patton, M. Q. (2001). Qualitative research and evaluation methods (3rd ed.). Thousand Oaks: Sage.

Reinders, H., \& White, C. (2016). 20 years of autonomy and technology: How far have we come and where to next? Language Learning \& Technology, 20(2), 143-154. Retrieved from http://1lt.msu.edu/issues/june2016/reinderswhite.pdf

Ruey, S. (2010). A case study of constructivist instructional strategies for adult online learning. British Journal of Educational Technology, 41(5), 706-720. https://doi.org/10.1111/j.1467-8535.2009.00965.x

Sadykova, G. (2013). Learning in new online cultures: East meets West. In C. Meskill (Ed.), Online teaching and learning (pp. 21-38). London, UK: Bloomsbury Academic.

Sadykova, G. (2014). Mediating knowledge through peer-to-peer interaction in a multicultural online learning environment: A case of international students in the US. The International Review of Research in Open and Distributed Learning, 15(3), 24-49. http://dx.doi.org/10.19173/irrodl.v15i3.1629

Sadykova, G., \& Dautermann, J. (2009). Crossing cultures and borders in international online distance higher education. Journal of Asynchronous Learning Networks, 13(2), 89-114. Retrieved from https://eric.ed.gov/?id=EJ862350

Salmon, G. (2004). E-moderating: The key to teaching and learning online. Psychology Press. 
Scollon, R., \& Scollon, S. W. (2001). Intercultural communication: A discourse approach. Malden, MA: Blackwell Publishing.

Shattuck, K. (2005). Glimpses of the global Coral Gardens: Insights of international adult learners on the interactions of cultures in online distance education (Doctoral dissertation). Retrieved from Penn State Electronic Theses and Dissertations database https://etda.libraries.psu.edu/paper/6685/

Shea, P., Hayes, S., Smith, S. U., Vickers, J., Bidjerano, T., Gozza-Cohen, M ... Tseng, C.-H. (2013). Online learner self-regulation: Learning presence viewed through quantitative content-and social network analysis. The International Review of Research in Open and Distance Learning, 14(3), 427-461. http://dx.doi.org/10.19173/irrodl.v14i3.1466

Shea, P., Hayes, S., Vickers, J., Gozza-Cohen, M., Uzuner, S., Mehta, R., ... Rangan, P. (2010). A re-examination of the community of inquiry framework: Social network and content analysis. The Internet and Higher Education, 13, 10-21.

https://doi.org/10.1016/j.iheduc.2009.11.002

Smart, K., \& Cappel, J. (2006). Students' perceptions of online learning: A comparative study. Journal of Information Technology Education: Research, 5(1), 201-219. Retrieved from https://www.learntechlib.org/p/111541/

Thorne, S. L. (2003). Artifacts and cultures-of-use in intercultural communication. Language Learning \& Technology, 7(2), 38-67. Retrieved from http://lit.msu.edu/vol7num2/thorne/default.html

Uzuner Smith, S., \& Mehta, R. (2013). The educational value of student talk in online discussions. In C. Meskill (Ed.), Online teaching and learning (pp. 119-136). London, UK: Bloomsbury Academic.

Vygotsky, L. (1981). The genesis of higher mental functions. In J. V. Wertsch (Ed.), The concept of activity in Soviet psychology (pp. 144-188). Armonk, NY: Sharpe.

Wang, M. (2007). Designing online courses that effectively engage learners from diverse cultural backgrounds. British Journal of Educational Technology, 38(2), 294-311. https://doi.org/10.1111/j.1467-8535.2006.00626.x

Ware, P. D., \& Kramsch, C. (2005). Toward an intercultural stance: Teaching German and English through telecollaboration. The Modern Language Journal, 89(2), 190-205. https://doi.org/10.1111/j.1540-4781.2005.00274.x

Warschauer, M. (1998). Online learning in sociocultural context. Anthropology \& Education Quarterly, 29(1), 68-88. https://doi.org/10.1111/j.1540-4781.2005.00274.x

Warschauer, M. (2002). Networking into academic discourse. Journal of English for Academic Purposes, 1(1), 45-58. https://doi.org/10.1016/S1475-1585(02)00005-X

Zhang, Z., \& Kenny, R. F. (2010). Learning in an online distance education course: Experiences of three international students. International Review of Research in Open and Distance Learning, 11(1), 17-36. http://dx.doi.org/10.19173/irrodl.v11i1.775

Zhao, N., \& McDougall, D. (2008). Cultural influences on Chinese students' asynchronous online learning in a Canadian university. Journal of Distance Education, 22(2), 59-80. Retrieved from http://www.jofde.ca/index.php/jde/article/view/37/559

\section{Funding}

The work of the first author was funded by the Russian Foundation for Basic Research (project No. 17-29-09128). 